\title{
Free charge of color illustrations: a new facility of Ichthyological Research
}

(C) The Ichthyological Society of Japan 2013

Ichthyological Research has introduced a new facility for all authors. Publication of color illustrations is free of charge in the print version if the use of color is considered to be essential by the editorial board. Even if the board does not approve free color publication, authors still may publish color illustrations provided they contribute to the extra costs involved (cost to author: 950 EUR $+19 \%$ VAT or 1,150 USD per article). Online publication of color illustrations is free of charge.

The Ichthyological Society of Japan

Seishi Kimura, President

Kunio Sasaki, Editor-in-Chief

Hisashi Imamura, Managing Editor of Ichthyological

Research 